\title{
MODA E SUSTENTABILIDADE: UM CONSUMO CONSCIENTE E OS CUIDADOS COM O PLANETA ${ }^{1}$ FASHION AND SUSTAINABILITY: CONSCIENT CONSUMPTION AND CARE FOR THE PLANET
}

\author{
Maryeli Corrêa Cheiram² e Elsbeth Leia Spode Becker ${ }^{3}$
}

\section{RESUMO}

Neste artigo objetiva-se refletir sobre o consumo consciente de moda e, dessa forma, engendrar a compreensão para o cuidado e o respeito com o Planeta. Abordam-se, também, questões de sustentabilidade, marcas que têm a preocupação sustentável e maneiras de ser sustentável enquanto consumidor, além da iminente importância da preservação da vida na Terra. Buscou-se, do mesmo modo, considerar a importância do ensino para promover a cultura da sustentabilidade. A metodologia está embasada no estado da arte, na perspectiva da pesquisa qualitativa e na abordagem descritiva, a partir de autores e de exemplos que proporcionam percepções para a sustentabilidade e o consumo consciente de moda. Pôde-se inferir que há uma emergente necessidade de uma nova cultura de consumo, que seja embasada nas microtendências e, assim, modificar o pensamento da humanidade, criando práticas econômicas, políticas e sociais para o reaproveitamento em benefício da natureza e dos seres humanos.

Palavras-chave: Microtendências, Reaproveitamento, Vida na Terra.

\section{ABSTRACT}

The article aims to reflect on sustainability and conscious consumption of fashion and, in this way, engender understanding for care and respect for the Planet. It also addresses sustainability issues, brands that have this sustainable concern and ways of being sustainable, in addition to the imminent importance of preserving life on Earth. We also sought to consider the importance of teaching to promote the culture of sustainability. The methodology is based on the state of the art, from the perspective of qualitative research and the descriptive approach based on authors and examples that provide insights into sustainability and conscious consumption of fashion. It could be inferred that there is an emerging need for a new consumer culture based on sustainability and, thus, to modify the thinking of humanity and create political and social economic practices for the benefit of nature and human beings.

Keywords: Microtrends, Reuse, Life on Earth.

1 Tipo de publicação: Pesquisa desenvolvida no Grupo de Pesquisa Humanidades, Linguagens e Práticas Docentes Mestrado em Ensino de Humanidades e Linguagens - MEHL.

2 Designer de Moda. Mestra em Ensino de Humanidades e Linguagens - Universidade Franciscana. E-mail: marycorreacontato@, outlook.com

3 Professora Doutora. E-mail: elsbeth.geo@gmail.com 


\section{INTRODUÇÃO}

A Terra não pertente ao homem. O homem à terra pertence. E tudo está interligado, como o sangue que une uma família. O que atinge a Terra atinge os filhos da Terra. Pois não foi o homem que teceu a trama da vida. Ao contrário, por ela foi tecido. E o que fizer à trama fará a si próprio (Discurso feito pelo Chefe Seattle, em 1854). ${ }^{4}$

Enriquecemo-nos pela utilização pródiga dos nossos recursos naturais e podemos, com razão, orgulhar-nos do nosso progresso. Chegou porém o momento de refletirmos seriamente sobre o que acontecerá quando as nossas florestas tiverem desaparecido, quando o carvão, o ferro e o petróleo se esgotarem, quando o solo estiver mais empobrecido ainda, levado para os rios, poluindo suas águas, desnudando os campos e dificultando a navegação. (Théodore Roosevelt, Conferência sobre a Conservação dos Recursos Naturais, 1908).

Notável era a capacidade de o Cacique Seatle proferir ideias profundas, usando a linguagem dos seus ancestrais da Tribo Duwamish. Ao ler o texto do discurso, percebe-se que as palavras dele vinham bem lá de dentro, como um sussurro soprado pelo vento ou um murmúrio suave, o qual vem de longe e, talvez, por isso ultrapassou as fronteiras das nações e do tempo e se tornou um discurso universal e atemporal, sendo retomado no século XX e, especialmente, nas primeiras décadas do século XXI.

No início do século XX, o presidente norte-americano Roosevelt alertou sobre os problemas gerados pelo progresso predatório e, novamente, chamou, para a pauta, a progressiva destruição dos recursos naturais da Terra. Não obstante, em 2000 foi divulgada a Carta da Terra que se definiu como uma declaração de princípios éticos fundamentais para a construção de uma sociedade global justa, sustentável e pacífica.

A partir da inspiração nestas duas epígrafes e do chamado da Carta da Terra, o artigo tem o propósito de refletir a respeito da sustentabilidade e do consumo consciente de moda e, assim, engendrar a compreensão para o cuidado e o respeito com o Planeta. O ser humano faz parte da Terra e, portanto, não deve ver o Planeta em que habita como algo fora de si, mas como algo do qual faz parte, afinal, a Terra é a sua casa.

Nussbaum (2015) defende a importância de as pessoas serem cidadãos do mundo, de se preocuparem com os problemas do mundo, com o aquecimento global, com os animais e a natureza, visto que tudo isso faz parte do indivíduo. Desse modo, é necessário se refletir sobre esses assuntos a fim de compreender melhor a natureza e os cuidados de que ela necessita, já que se vive em uma sociedade capitalista, que, diariamente, explora os meios naturais.

O ser humano está em constante mudança e, principalmente a partir da Revolução Industrial, interfere, cada vez mais, nos recursos naturais em benefício da sobrevivência e, em especial, pensando na geração de riqueza e no lucro. A Terra, por sua vez, evolui em sua trajetória geológica e biológica, porém reage à maneira indiscriminada que a exploração humana exerce sobre os recursos naturais.

4 Discurso do Cacique Seattle e que foi proferido ao presidente norte-americano Franklin Pierce em 1854 (depois de o governo ter dado a entender que desejava adquirir o Território da Tribo Duwamish). Texto de domínio público, distribuído pela ONU. 
Além do grande aumento populacional ocorrido a partir do século XX, há, também, o consumo exagerado e o descarte indiscriminado de alimentos, produtos e embalagens. Ademais, o processo produtivo se dá, cada vez mais, em maior escala, seja na agricultura, seja na indústria, a fim de proporcionar e de incentivar o aumento do consumo e da geração de lucro.

$\mathrm{Na}$ área da moda, isso não é diferente! Consome-se e descarta-se em grandes quantidades. Castilho; Martins (2005) esclarecem que a moda tem um significado próximo à construção da identidade subjetiva e individual do indivíduo e está presente a partir das mudanças cíclicas e estilísticas, as quais são propagadas e aceitas. Em decorrência disso, o desejo de consumo aumenta, já que se acredita que o próprio sistema de moda instiga as pessoas a consumirem (ROCAMORA, 2002; WISSINGER, 2009). Ela é considerada como um sistema de significados complexos, pois exerce influência no estilo de vida das pessoas, nos interesses individuais e até na maneira de pensar dos indivíduos. Assim, a moda configura-se como um diálogo social (RAFFERTY, 2011; SANDIKCI; GER, 2010; THOMPSON; HAYTKO, 1997).

Para McCracken (1986), a partir do sistema de moda e da publicidade constitui-se uma trajetória e um movimento do significado cultural, na sociedade moderna, que promovem o movimento de significado do mundo culturalmente constituído para os bens de consumo e os rituais de consumo auxiliam na constante renovação do interesse pelo consumo.

Diante desse sistema cíclico e efêmero de consumo, as pessoas precisam adquirir uma nova consciência e ter uma preocupação com a sustentabilidade, ou seja, há a necessidade de vivenciar-se um novo ciclo e pensar em adquirir produtos que tenham uma vida útil longa. Nessa linha de pensamento, neste artigo, são abordadas questões de sustentabilidade, mencionadas marcas que têm essa preocupação sustentável e maneiras de ser sustentável. Além disso, aborda-se a importância do ensino para o pensamento sustentável e das características da Terra.

\section{METODOLOGIA}

A metodologia está embasada no estado da arte, na perspectiva da pesquisa qualitativa e na abordagem descritiva, a partir de autores e de exemplos que proporcionam percepções para a sustentabilidade e o consumo consciente de moda. O percurso do pensamento da escrita foi engendrado na cosmovisão da relação do ser humano com o meio através do espaço habitável e como pode determinar sua existência em harmonia com a natureza, por meio da moda como identidade, linguagem, representação social.

A pesquisa qualitativa, segundo Malhotra (2006), é baseada em pequenas amostras, que permitem percepções e compreensão do contexto do problema. Toda metodologia aponta o caminho a ser seguido, norteando as ações do pesquisador, por meio das fontes e de ferramentas disponíveis. 


\section{MODA E CONSUMO}

Na concepção de Palomino (2003), a partir do final da Idade Média, século XV, na Borgonha, o conceito de moda surgiu e difundiu-se em função da necessidade de copiar as roupas dos nobres pelos burgueses, por conta da aproximação das pessoas na área urbana, sendo a moda um sistema que faz o acompanhamento do vestuário e do tempo, no dia a dia, ou em contextos maiores, como o político, o social e o sociológico. "A moda serve como reflexo das sociedades à volta" (PALOMINO, 2003, p. 14).

$\mathrm{Na}$ literatura é possível perceber que a moda é carregada de conceitos, de conteúdos e de contextos expressivos, os quais retratam diferentes épocas em que o homem viveu. Dessa forma, "a moda é o espelho da história" (EMBACHER, 1999, P. 23). Ela, ainda, é "uma realidade sócio-histórica característica do Ocidente e da própria modernidade" (LIPOVETSKY, 1989, p. 10).

A moda pode ser pensada como a repetição dos padrões visuais no seu modo de vestir. Os autores Goellner; Jaeger; Figueira (2010) pontuam que ela pode ser entendida como um sistema de produção e de comunicação que introduz mudanças de comportamento e de aparência de acordo com a cultura e com os ideais de um determinado tempo e lugar.

Segundo Kotler; Keller (2006, p. 172), “o comportamento de compra do consumidor é influenciado por fatores culturais, sociais, pessoais e psicológicos. Os fatores culturais exercem a maior e mais profunda influência”. Ainda, esses autores afirmam que os fatores culturais podem ser divididos em cultura, subcultura e classe social, em que a cultura é formada pelos valores, pelas preferências e pelos comportamentos de instituições com os quais a pessoa convive. Já as subculturas fornecem identificação e socialização mais específicas para seus membros. Por fim, as classes sociais são "divisões relativamente homogêneas e duradouras de uma sociedade, que são hierarquicamente ordenadas e cujos integrantes possuem valores, interesses e comportamentos similares” (KOTLER; KELLER 2006, p. 176).

Além disso, as pessoas consomem de maneiras diferentes e por diversos motivos, sendo a classe social um fator que deve ser levado em conta. O que leva as pessoas consumirem, conforme Kotler e Keller (2006), são as referências que elas possuem, são os chamados grupos influenciadores, em que cada papel se constitui de um status social, em que não há uma preocupação com o planeta, mas sim com a autoimagem e o ego.

"O desenvolvimento industrial e sua mecanização crescente vai tornar os produtos reproduzíveis em série e, portanto, acessíveis a um maior número de pessoas" (LIPOVETSKY; ROUX, 2005, p. 31). Com base nessa afirmação, percebe-se que a produção dos produtos em série é mais barata e, por isso, alcança o maior número de pessoas, porém não há uma preocupação com a durabilidade do produto, nem com a sua qualidade.

Diante do exposto, é possível constatar que deve haver um compromisso para uma grande mudança na maneira de as pessoas consumirem. Elas devem ter um olhar mais crítico sobre o consumo, 
pois esse comportamento afeta diretamente a vida na Terra. A moda pode ser efêmera e cíclica, é um movimento de tendências que saem de cenário, mas, em algum momento, retornam. Desse modo, é importante consumir produtos que signifiquem permanência através do tempo.

\section{SUSTENTABILIDADE NO DESIGN}

Na concepção de Nussbaum (2015), todos somos cidadãos do mundo e, em decorrência disso, é importante que se cuide da natureza; é preciso manter esse patrimônio quando se é parte dele. A sustentabilidade, nesse cenário, é indispensável, já que é necessário que exista preocupação em preservar e impactar no menor grau possível nos recursos naturais. Na moda, é importante o ciclo de vida dos produtos, uma vez que eles não devem mais ir para o descarte, mas adquirir oportunidades de serem replanejados e/ou redefinidos para evitar o descarte. No entanto, não esta prática ainda não é comum, pois “As pessoas são emotivas, volúveis e inconstantes, e vivem em uma sociedade cujos valores e crenças estão em contínua transformação" (FLETCHER; GROSE, 2011, p. 78).

Embora se possa estar em constante transformação e evolução, precisa-se estabelecer valores que não sejam volúveis, os quais permaneçam ao longo da vida. Partindo desses princípios, é mister se pensar em formas de reaproveitar os materiais para que haja um consumo consciente e com significado. As Ecobags (bolsas sustentáveis) são um exemplo de como se pode reutilizar. Segundo Pacce (2009), elas surgiram na década de 2000 e geraram a atenção e a preocupação de muitas marcas, que se inspiraram e fizeram seu modelo sustentável.

Pensando nessas questões, o designer Antonio Scarponi e sua equipe da Conceptual Devices, Ecodesenvolvimento (ECOD, 2010) produziram vídeos nos quais mostram como um simples moletom pode ser multifuncional e se transformar em sacola, travesseiro, bolsa para notebook, mochila e suporte para bebê. E o mais notável e importante é que o moletom não precisa ser cortado ou descaracterizado (Figura 1). Essa é uma maneira simples, mas eficaz, de possuir um objeto com várias funcionalidades e utilidades, fazendo as pessoas consumirem menos.

De forma similar, o reaproveitamento do jeans também pode originar bolsas, porta-livros, porta-trecos, capas de livros, agendas, artigos de decoração e forro para móveis (Figura 2). Para tanto, é necessário ser criativo antes de pensar no descarte de qualquer produto e pensar nas utilidades que cada um terá antes mesmo de adquiri-lo, evitando, assim, comprar produtos que não terão funcionalidade. Logo, quando se adquire um produto com funcionalidade, e ele estraga ou deixa de ser funcional, pode-se encontrar uma função para ele, visto que os pertences de cada pessoa são de sua responsabilidade e, atualmente, jogar as coisas no lixo impacta no meio ambiente. 
Figura 1 - Referências ao moletom multifuncional.

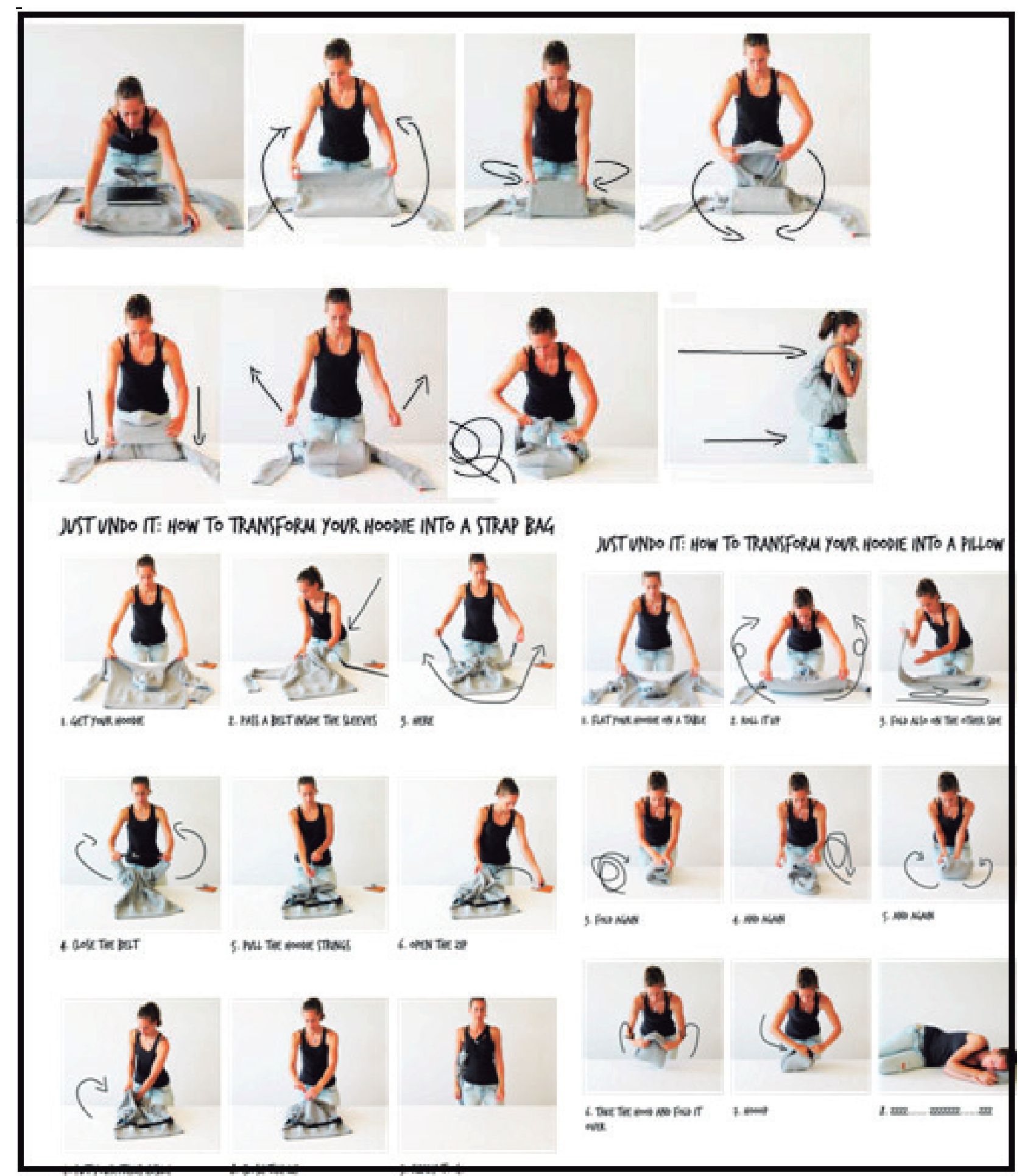

Fonte: Ecodesenvolvimento (2010). Disponível em: https://bit.ly/3u4fbM5 
Figura 2 - Painel de sustentabilidade a partir do jeans.

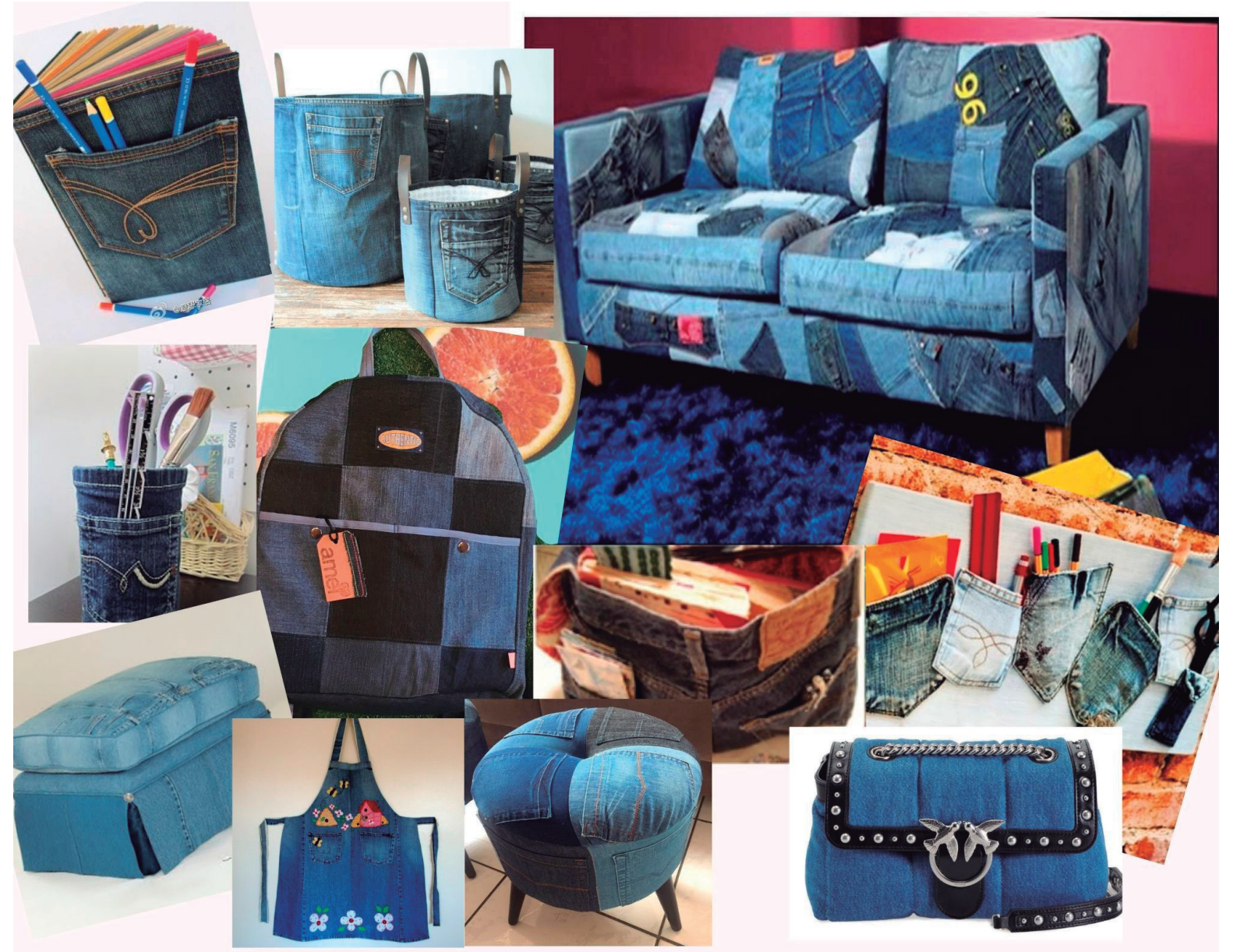

Fonte: Elaborado pelas autoras.

Pode-se observar, a partir das imagens, que o conceito de sustentabilidade pode ser uma ferramenta que ajuda o designer a criar um olhar para os objetos que as pessoas deixam de usar e/ou descartam. Isso também é empreender, pois consiste no fato de inovar em meio a algo que já existe e pode ser reaproveitado. Desse modo, os materiais citados, assim como outros que existem, podem ser reformados e remodelados de maneira consciente pelo consumidor.

\section{O consumo e as marcas (microtendências)}

Microtendências são denominadas as marcas sustentáveis, a que poucas pessoas aderem, geralmente, por falta de conhecimento e/ou pela ausência de uma cultura de preservação baseada na reutilização. Uma marca que se preocupou com a sustentabilidade foi a ÖUS, a qual existe, desde 2008, com uma linha de tênis totalmente sustentáveis. Ela lançou a coleção ECOLAB (Figura 3) que utilizou apenas materiais orgânicos, de origem vegetal, reciclados e ecologicamente corretos. Os tênis chamam atenção por suas estampas, e as cores deles têm inspiradas em histórias e lugares que permeiam o universo urbano. 
Figura 3 - Referências de microtendências

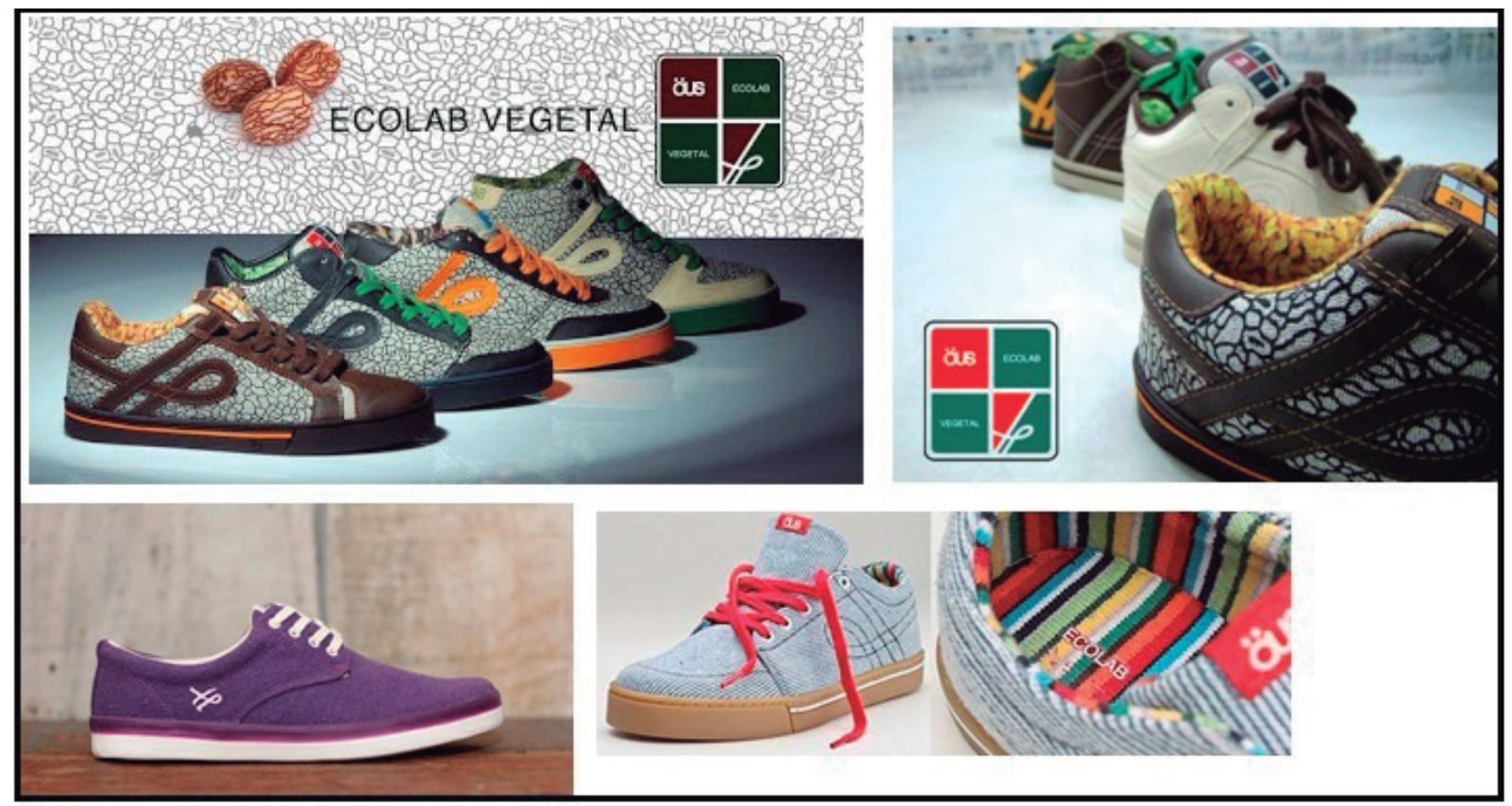

Fonte: ÖUS. Disponível em: http://www.ous.com.br/blog/

Outra marca sustentável, e com visibilidade no mercado, é a Insecta Shoes (Figura 4), uma marca nova no mercado de Porto Alegre (RS), que atua desde 2014, e comercializa uma linha de sapatos veganos, ecológicos, feitos a mão e sustentáveis. A Insecta Shoes tem pares exclusivos e confortáveis. Os sapatos são feitos com tecidos de diferentes tendências e temáticas, englobando tudo isso em um design impecável, colorido e de muito conforto.

Os sapatos dessa marca são feitos de reaproveitamento a partir de roupas encontradas em brechós e de tecidos feitos com garrafa pet. Além de sapatos, a marca também fabrica acessórios. Dessa forma, a marca busca aproveitar ao máximo os materiais que utiliza em seus processos de produção. Isso é um ponto positivo para quem busca sapatos exclusivos, pois, dificilmente, haverá sapatos iguais, levando em conta sua forma de produção.

Figura 4 - dados da marca Insecta Shoes

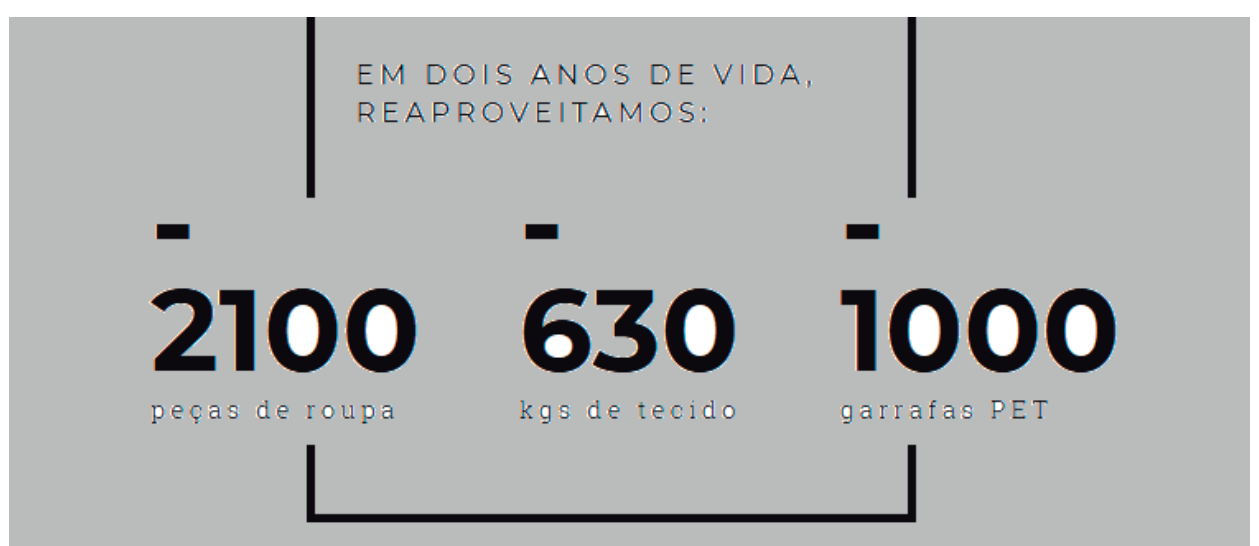

Fonte: Insecta Shoes. Disponível em: https://www.insectashoes.com 
Esses dados, os quais foram informados pela marca (figura 4), mostram o quanto se pode aproveitar de materiais durante dois anos de existência da marca. Ela está há com 5 anos no mercado, e seus números continuam aumentando e dando vida a roupas que não eram mais usadas, nem podiam ser vendidas, e a garrafas pet que seriam jogadas no meio ambiente. Sabe-se que o plástico demora muito tempo para se decompor e que a poluição causada pelo excesso de lixo gera estragos irreparáveis à Terra.

Dessa forma, a marca está prolongando a vida útil dos produtos e preservando a natureza. A Insecta Shoes não vende apenas calçados, ela vende também um estilo de vida, conceitos, valores ecológicos e uma maneira de repensar o consumo dos produtos (Figura 5).

Figura 5 - Valores da marca Insectashoes

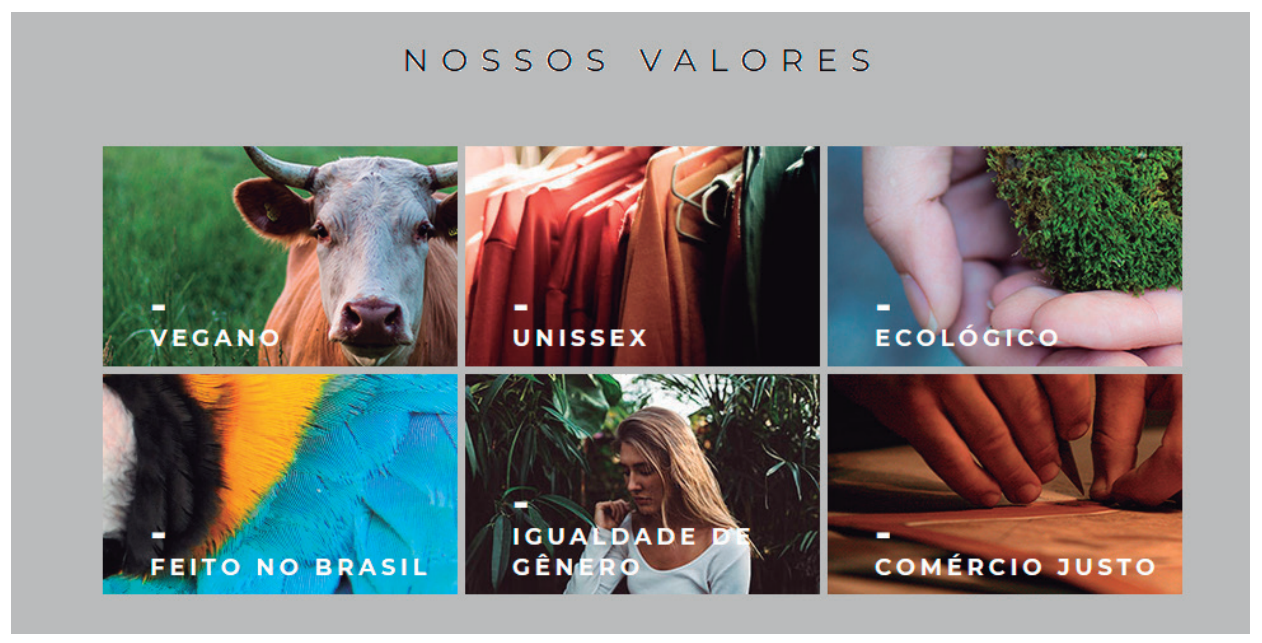

Fonte: Insectashoes. Disponível em: https://www.insectashoes.com

A figura 5 aponta que a marca tem valores bem construídos e que se preocupa com os meios de produção. Na loja existente em Porto Alegre, as entregas de compras são realizadas com a utilização de uma bicicleta. Então, a marca prova que não basta só ter uma visão sustentável, é preciso ter atitudes sustentáveis. Além disso, ela tem um blog, que pode ser acessado pelo próprio site. No blog, há textos a respeito da sustentabilidade e diversas dicas para manter iniciar e manter pequenas ações sustentáveis no dia a dia, mas que, no conjunto, fazem grande diferença para a manutenção de uma vida mais saudável no Planeta.

Em uma matéria feita pela Revista ELLE foi mencionado que os termos clothing swap, consumo consciente e produção sustentável, têm sido mais abordados nos últimos tempos e que tem gerado uma mudança de comportamento no nosso dia a dia, ou seja, estamos nos tornando consumidores mais questionadores. A autora, Levy (2015), afirma que tem se tornado mais frequente aparecerem ideias para que as pessoas consumam menos, a saber: trocar de roupas entre as pessoas, doar roupas e objetos, customizar peças são alguns exemplos de maneiras de consumir conscientemente. 
A partir dos dados apresentados, pode-se inferir de que o mercado já tem marcas preocupadas com a sustentabilidade e que os produtos, além de bem executados, são de qualidade e instigam o consumo de consumidores conscientes.

\section{A IMPORTÂNCIA DE UM CONSUMO CONSCIENTE}

Dentre as dez capacidades centrais, necessárias ao ser humano, citadas por Nussbaum (2015), há a oitava capacidade: “Outras espécies. Ser capaz de viver uma relação próxima e respeitosa com animais, plantas e o mundo da natureza". Ela implica diretamente com o nosso consumo, pois, se ele for exagerado, pode levar ao fim de nossos recursos naturais.

"Nossas decisões mais simples como consumidores afetam o padrão de vida de pessoas de países distantes que estão envolvidos na produção de bens utilizados por nós" (NUSBAUM 2015). Nessa afirmação, a autora se refere também às condições de trabalho, as quais devem ser justas. Ainda, ela nos instiga a pensar de onde os produtos que são usados, todos os dias, vêm, como são produzidos e por quem são produzidos.

A autora afirma que saber dessas origens implica diretamente na cidadania, visto que se deve ter consciência dos grupos que compõem nossa sociedade, de suas diferentes tarefas e condições de vida. Acima de tudo, é preciso criar uma preocupação com eles, pois fazemos parte do mesmo lugar e não podemos ver as pessoas como distantes de nós.

"Isso quer dizer que nunca vimos o mundo como um mundo, nunca entendemos a interação dinâmica entre as nações e povos que compunham, nunca chegamos nem mesmo a compreender como, ou onde, os produtos que usamos diariamente eram produzidos”. (NUSSBAUM, 2015, p. 87)

Assim, devemos nos sentir cidadãos do mundo, mantendo a preocupação com o consumo e em nossas atitudes. É necessário se perceber o mundo em sua totalidade. Devemos começar a repensar isso a partir das crianças. Dewey (2004) praticava ensinamentos que instigavam as crianças a perguntar sobre o processo de produção dos objetos que usavam em seus cotidianos. Elas aprendiam a tecer a roupa, de onde vinham os materiais e de que maneira chegavam até elas. Segundo o autor, isso as fazia enxergarem o mundo em sua totalidade e não apenas o que estava embaixo de seus narizes.

As crianças também cuidavam dos animais e dos jardins, e “o importante”, concluiu ele: “... é que cada um receba a educação que lhe permita perceber todo o significado generoso e humano que existe em suas atividades diárias" (DEWEY, 2004, p. 54).

Não se pode esquecer que, cada um de nós, precisa de muitas pessoas, todos os dias, para otimizar a cadeia produtiva da qual também somos dependentes. Sob este aspecto, é importante pensar no trabalho de cada um e na importância deste trabalho na cadeia produtiva e avaliar as maneiras possíveis de tornar a ação de cada um mais sustentável e, principalmente, contribuir para isso, consumindo e preferindo produtos de consumo sustentáveis. 


\section{ENSINAR E APRENDER SUSTENTABILIDADE}

Com o intuito de se ter um ensino sustentável, é preciso entender os conceitos sobre a natureza. A ecologia é uma ciência que estuda os seres vivos e as suas relações com o ambiente (FONSECA E CALDEIRA, 2008). Philippi Jr; Pelicioni (2013) afirmam que o homem tem a capacidade de alterar o meio em que vive e adequá-lo à sua sobrevivência. Todavia, nos dias atuais, é perceptível que essas alterações têm prejudicado o meio ambiente e a qualidade de vida na Terra. Isso tem acontecido, em grande parte, em decorrência, do consumo inconsciente.

Fonseca; Caldeira (2008) observam que esses acontecimentos têm chamado a atenção de ambientalistas, o que gerou fóruns mundiais como a Conferência de Estocolmo (1972) e o Rio -92 (1992). Esses fóruns tinham, como contraponto, o desenvolvimento sustentável, levando em conta os custos ecológicos da manutenção de nossa sociedade para criar um novo modelo de organização social e de produção (FONSECA; CALDEIRA, 2008).

Nesse contexto, percebe-se que há preocupação e necessidade de se ter um consumo consciente, mas também meios de produção justos com as pessoas que produzem (preocupação com as horas de trabalho e com as condições em que se trabalha) e com o meio ambiente. Logo, não se pode pensar em produtos que tenham, como destino, o lixo. Necessita-se pensar sobre quais impactos ambientais a produção deles gerará para a natureza.

$\mathrm{Na}$ indústria da moda, existem várias notícias a respeito desses problemas, já que existe trabalho escravo em facções de costura, sem falar das más condições de produção. Isso ocorre não só com roupas, como também na produção de acessórios, celulares, dentre outros. Diante disso, é importante

voltar à ideia de que é necessário se entender os conceitos de ecologia, pois eles são fundamentais para a formação de seres humanos como cidadãos (FONSECA; CALDEIRA, 2008).

Potter (2001) pontua que o ambiente natural não é ilimitado e, por isso, é importante que as pessoas saibam usar o conhecimento, que entendam como empregar o conhecimento para seu próprio bem e para o bem social. Ter conhecimento para saber agir com conhecimento, usar de forma adequada o conhecimento, a fim de que seja gerada uma ciência da sobrevivência. $\mathrm{O}$ autor, igualmente, afirma que existem dois conceitos importantes para a construção da sabedoria e da bioética, quer sejam: o conhecimento biológico e os valores humanos. Ademais, o autor também aponta para a necessidade de combinar os conhecimentos humanísticos com a biologia e, assim, reorganizar os conceitos já existentes e suas prioridades (POTTER, 2001).

Machado (1982) defende que só cuidamos, respeitamos e preservamos aquilo que conhecemos. Portanto, a ignorância pode nos levar à distorção da realidade. A partir do exposto, percebe-se o quanto conhecer os conceitos é importante. Dessa maneira, é preciso observar os hábitos diários para captar o quanto a natureza nos serve; o quanto o homem precisa, diretamente, da natureza e, por isso, 
ele precisa conhecê-la com o propósito de que possa dar a ela a devida importância. Só assim será possível mudar os meios de produção.

Alves (2016) considera que se deve buscar, no pensamento ético-filosófico, um esclarecimento para as inquietações do homem no que diz respeito às relações que se estabelece com a natureza e consigo mesmo. É importante também que se considere o papel da comunidade mundial, uma vez que só dessa maneira será possível existir, no futuro, a sobrevivência do Planeta. "O futuro não espera para chegar, o futuro não é uma distância que se aproxima; o futuro é uma emergência que se anuncia e que exige resposta ética. Portanto, não é exagero afirmar que a humanidade nunca teve tanta responsabilidade" (ALVES, 2016, p. 59).

Desse modo, é necessário entender que o dia de hoje é o futuro e que se deve agir de maneira ética e ter responsabilidade com o Planeta. Em decorrência disso, é necessário que exista o ensino de uma nova cultura, o qual modifique e intensifique os cuidados com o amanhã. Nesse aspecto, não se pode considerar como ensino somente o transmitido de professor para aluno, mas sim aquele que propõe uma nova cultura e novos hábitos, que ajudem as pessoas a viverem melhor e a compreenderem a condição humana (ALVES, 2016).

\section{CONSIDERAÇÕES FINAIS}

O ser humano é o único animal inserido em todos os ecossistemas ambientais e, por ter uma natureza racional, pode salvar o Planeta de si mesmo ou colocar em risco a própria existência. Por isso, é necessário existir uma preocupação com os cuidados com a vida na Terra, pois o fim do Planeta significaria o fim dos seres humanos e de todo o ecossistema, ou seja: se o homem acabar com os recursos naturais, colocará em extinção a própria humanidade.

Existe uma preocupação em se construir uma sociedade sustentável, levando-se em conta que as atividades humanas são insustentáveis. É importante que o homem perceba isso e se enxergue como uma ameaça para a própria vida a fim de que ele possa compreender a importância de cuidar do espaço em que vive, já que, como já afirmado anteriormente, o Planeta não está distante do ser humano e as pessoas necessitam da Terra. Estar cuidando do Planeta em que se vive é cuidar da própria vida. Logo, é salutar se ter preocupação com o consumo consciente.

Assim, é importante que se pense em modificar o pensamento da humanidade; em criar práticas econômicas, políticas e sociais em benefício dos seres humanos. Conclui-se que é necessário mudar os hábitos de quem vive no Planeta para que se possa construir uma sociedade sustentável e de consumo consciente, salvando a vida humana na Terra. 


\section{REFERÊNCIAS}

ALVES, Marcos Alexandre. O princípio ético da responsabilidade: apelo por um ensino científico prudente. Comunicações Piracicaba v. 23 n. 2 p. 53-68. Ago. 2016. Disponível em: http://dx.doi. org/10.15600/2238-121X/comunicacoes.v23n2p53-68 Acesso em 25 nov. 2020.

CASTILHO, Katia; MARTINS, Marcelo. Discursos da Moda e semiótica, Design e corpo. Editora Anhembi Morumbi, 2005.

DEWEY, John. Democracy and Education. Nova York: Macmillan, 1916; reed. Mineola, NY; Dover, 2004.

ECOD. Conceito de Ecodesenvolvimento na Moda. 2010. Disponível em: https://bit.ly/3CySYJi. Acesso: Maio, 2021.

FONSECA, Gustavo. CALDEIRA, Ana Maria de Andrade. Uma reflexão sobre o ensino aprendizagem de ecologia em aulas práticas e a construção de sociedades sustentáveis. R.B.E.C.T., v. 1, n. 3, set./dez. 2008. Disponível em: https://bit.ly/2W2Vxnn. Acesso em 24 Nov. 2020

EMBACHER, Airton. Moda e identidade: a construção de um estilo próprio. São Paulo: Editora Anhembi Morumbi, 1999.

FLETCHER, Kate; GROSE, Lynda. Moda e sustentabilidade, Design para mudança. São Paulo, editora Senac, 2011.

GOELLNER, Silvana Vilodre; JAEGER, Angelita Alice; FIGUEIRA, Márcia Luiza Machado. Mulheres e esporte: Invisibilidades visíveis no skate e no fisiculturismo. Gênero, v.10, p. 293- 310. Niterói 2010. Disponível em: https://bit.ly/3kwj4qf. Acesso em: 21 Nov. 2020

KOTLER, Philip; KELLER, Kevin Lane. Administração de Marketing. 10. ed. São Paulo: Pearson Prentice Hall, 2006.

LEVY, Nathalia. Iniciativas que mostram como o consumo de moda está mudando. Revista ELLE, Publicado em 16 nov 2015. Disponível em: https://bit.ly/2XMEg2s. Acesso em: maio 2021. 
LIPOVETSKY, Gilles. O Império do Efêmero: a moda e seu destino nas sociedades modernas. São Paulo: Companhia das Letras, 1989.

LIPOVETSKY, Gilles; ROUX, Elyette. O luxo eterno: da idade do sagrado ao tempo das marcas. São Paulo: Companhia das Letras, 2005.

MACHADO, Angelo Barbosa Monteiro. Conservação da natureza e educação. In: Anais... Congresso Nacional sobre essências Nativas, campos do jordão, São Paulo. p. 109-108, 1982.

MALHOTRA, Naresh. Pesquisa de marketing: uma orientação aplicada. Porto Alegre: Bookman, 2006.

MCCRACKEN, Grant. Culture and consumption: A theoretical account of the structure and movement of the cultural meaning of consumer goods. Journal of Consumer Research, p. 71-84.1986.

PHILIPPI JR, Arlindo; PELICIONI, Maria Cecília Focesi. Educação ambiental e sustentabilidade. Coleção ambiental, 2. ed. Barueri: Manole, 2013.

NUSSBAUM, Martha Craven. Sem fins lucrativos: por que a democracia precisa das humanidades. tradução fernando santos. São Paulo. Editora WMF Martins Fontes, 2015.

PACCE, Lilian. Ecobags, moda e meio ambiente. Editora Senac. São Paulo, 2009.

PALOMINO, Erika. A Moda. Publifolha, São Paulo, 2003.

POTTER, Van Rensselaer. Bioética: ponte para o futuro/ van Rensselaer Potter; tradução de Diego Carlos Zanella. Sâo Paulo: Edição Loyola, 2016.

THOMPSON, Craig Jay; Haytko, Diana. Speaking of fashion: consumers' uses of fashion discourses and the appropriation of countervailing cultural meanings. Journal of Consumer Research, 24(1), p. 15-42. 1997.

WISSINGER, Jane. Modeling Consumption Fashion modeling work in contemporary society. Journal of Consumer Culture, 9(2), p. 273-296. 2009. 
RAFFERTY, Karen. Class-based emotions and the allure of fashion consumption. Journal of Consumer Culture, 11(2), p. 239-260. 2011.

ROCAMORA, Agnes. Fields of Fashion Critical insights into Bourdieu's sociology of culture. Journal of Consumer Culture, 2(3), p. 341-362, 2002.

SANDIKCI, Özlem; GER, Guliz. Veiling in style: how does a stigmatized practice become fashionable?. Journal of Consumer Research, 37(1), p. 15-36, 2010. 